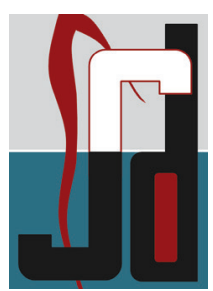

CASE SERIES

\title{
SPECT/CT image fusion in unilateral condylar hyperplasia - Report of a case and review of literature
}

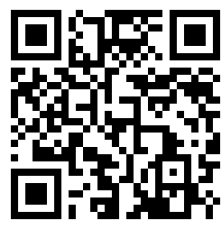

Sanjay Pasupathy ${ }^{1}$, Karthik Ragupathy ${ }^{2}$

\section{Introduction}

Condylar hyperplasia is one of the rare entities among temporomandibular disorder $\mathrm{s}$. The disease commonly affects the younger growing population. Early recognition and immediate management is essential to avoid complex abnormal growth related complications like facial asymmetry. In the past conventional skeletal scintigraphy was the only useful investigation for the determination of active growth status of the affected condyle. Computer tomography (CT) gives visualization of anatomic structures and abnormalities but lacks functional information. Single photon emission computed tomography (SPECT) is a recent investigative technology which will show the existance of active growth changes in these cases better than conventional scintigraphy. SPECT/CT fusion refers to the imaging technique that combines the functional information from SPECT with the anatomical information from CT into one set of images. We report a case of unilateral condylar hyperplasia in which this hybrid SPECT/CT image fusion was effectively used.

\section{Case report}

A 18 year old lady reported to our hospital with complaints of facial asymmetry existing for two years. Patient also reported that the asymmetry was increasing day by day. Physical examination revealed mandibular midline shift to right side, left side scissor like cross bite and deviation of mandible towards right side while opening.

Panaromic radiograph (Figure 1) revealed severe remodeling and enlargement of left condylar head with elongated neck. The right side condyle was apparently normal.

A provisional diagnosis of left side hemimandibular elongation (Type I condylar hyperplasia) was made.
To know the functional growth activity of the affected condyle, skeletal scintigraphy and the new SPECT/CT image fusion investigations were advised.

Conventional skeletal scintigraphy ( Figure 2) revealed the presence of "hot spot" (highly active growth activity) in left condyle and apparently normal activity in righy condyle. The hot spot is diffuse and the exact location is not visible in these scintigraphy images.

SPECT images clearly showed the enhanced growth activity in left condylar head region (Figure 3). The CT images vividly depicted the presence of abnormal irregular enlargement of left condylar head (Figure 4). The fusion images of both the SPECT and CT (Figure 5) amazingly showed the accurate anatomical location of the hot spot in the enlarged left condylar head. The fused images were shown three dimensionally in axial, sagittal and coronal sections. A 25 mci Tc99 radio isotope injection was given prior for SPECT imaging.

\section{Discussion}

Nuclear medicine studies are largely based on function. They become more meaningful, accurate and reliable when supported by precise anatomical localization. High quality SPECT images focus on functional abnormalities that appear earlier than the anatomical changes seen with computed tomography (CT) alone. SPECT and positron emission tomography (PET) are very reliable and accurate methods for detecting malignancies and other related abnormalities. However, these methods do not provide the much needed anatomical landmarks to exactly localize the lesions with high precision [1]. On the other hand, CT pinpoints disease location by providing the anatomical details where the lesion resides. SPECT/CT fusion imaging, acquired in a single examination, inherently registers two images for a complete pathology picture. 
It combines anatomical studies with functional detail and as such, it overcomes the drawbacks of both modalities and emphasizing their individual strengths [2-4]. Thus, it increases the diagnostic accuracy of SPECT as coregistered data have shown to be useful in the evaluation of patients with different diseases. This image fusion technology is already in use as a valuable diagnostic tool in detecting malignancies [5], assessing myocardial perfusion [6,7], bone infections [8] etc.

The primary disadvantage of the technique however is the low-dose CT scan. The images obtained are of low resolution. Nevertheless they are very useful for spatial localization and fusion with SPECT data. As such, it cannot be a substitute for $\mathrm{CT}$ with high resolution diagnostic quality images. It is also worthwhile to note that radiation burden due to $\mathrm{CT}$ is very low at $0.5 \mathrm{mSv}$ as the $\mathrm{X}$-ray tube operates at $2.5 \mathrm{~mA}[4,9]$.

SPECT/CT is not to be viewed as a technique allowing simple summation of different data. Rather, it efficaciously displays anatomical and physiological relationships. It facilitates both understanding of diagnostic information and characterization of underlying physiology (4). It aids not only in diagnosis and follow-up but also in the selection and planning of appropriate therapeutic options.

Use of Spect alone in detecting growth anomalies in condylar hyperplasia [10-12] and in normal condyles[13] has been reported. But SPECT/CT fusion in condylar hyperplasia has not been reported in literature so far.

Based on the findings given by SPECT/CT fusion, a high condylectomy and sliding genioplasty was done to this patient and after a follow up for six months no recurrence noted so far.

\section{Conclusion}

SPECT/CT fusion is a very useful investigation which allows for more accurate diagnosis and thus improved outcomes and treatment in patients with condylar hyperplasia.

\section{References}

1. Schillaci O, Simonetti G. Fusion imaging in nuclear medicine applications of dual-modality systems in oncology. Cancer Biother Radiopharm 2004; 19(1): 1- 10.

2. Von Schulthess GK, Pelc NJ. Integrated-modality imaging:
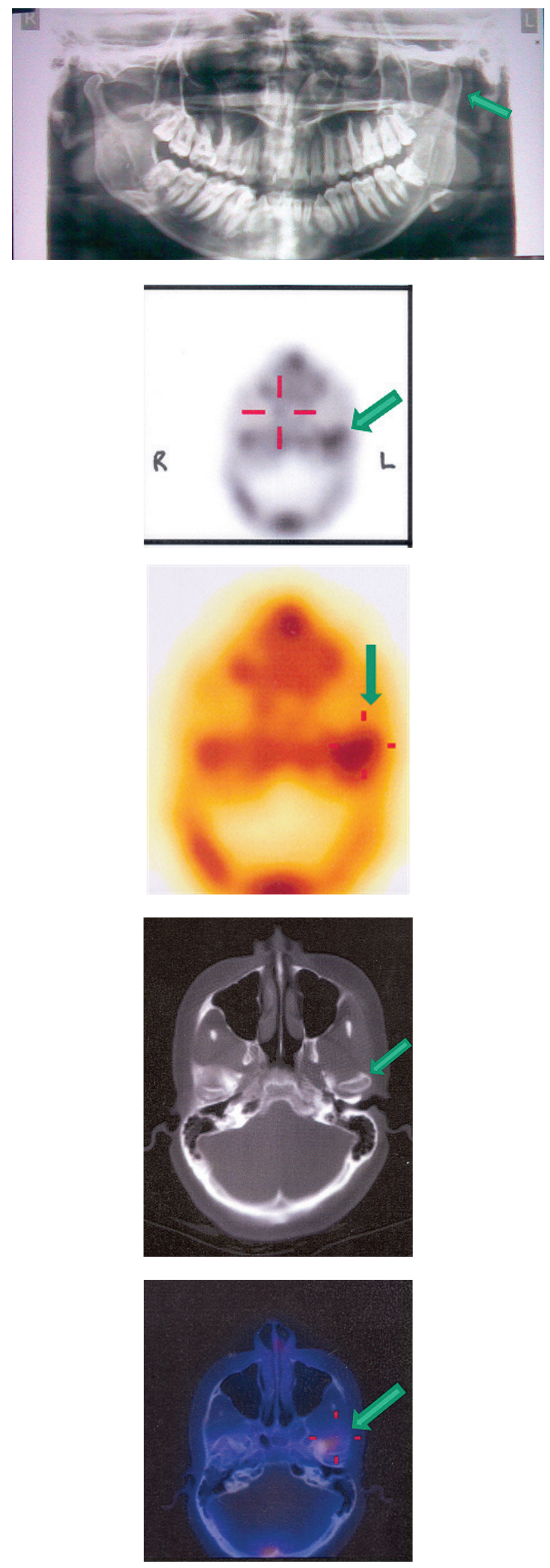
the best of both worlds. Acad Radiol 2002; 9:1241-4.

3. Keidar Z, Israel O, Krausz Y. SPECT/CT in tumor imaging: technical aspects and clinical applications. Semin Nucl Med $2003 ; 33: 205-18$.

4. Schillaci O. Hybrid SPECT/CT: a new era of SPECT imaging? Eur J Nucl Med Mol Imaging 2005; 32:521- 24.

5. Israel O, Keidar Z, Iosilevsky G, Bettman L, Sachs J, Frenkel A. The fusion of anatomic and physiologic imaging in the management of patients with cancer. Semin Nucl Med 2001; 31(3): 191-205.

6. Bockisch A, Freudenberg LS, Schmidt D, Kuwert T. Hybrid imaging by SPECT/CT and PET/CT: proven outcomes in cancer imaging.. Semin Nucl Med. 2009 Jul; 39(4):276-89.

7. Kaufmann PA, Di Carli MF. Hybrid SPECT/CT and PET/CT imaging: the next step in noninvasive cardiac imaging. Semin Nucl Med. 2009 Sep; 39(5):341-7.

8. Chiara Bruni; Federico Padovano; Laura Travascio; Orazio Schillaci; Giovanni Simonetti. Usefulness of hybrid SPECT/CT for the ${ }^{99 \mathrm{~m} T \mathrm{~T}-H M P A O-l a b e l e d ~ l e u k o c y t e}$ scintigraphy in a case of cranial osteomyelitis. Braz J Infect Dis vol.12 no.6 Salvador Dec. 2008

9. Kneifel S. Radiation dose and radiation protection. In: von Schulthess GK (Ed), Clinical molecular anatomic imaging. Philadelphia: Lippincott 2003. p. 68-71.
10. Dimonte M, Inchingolo F, Minonne A, Arditi G, Di Palma G. Bone SPECT in management of mandibular condyle hyperplasia. Report of a case and review of literature. Minerva Stomatol. 2004 May;53(5):281-5.

11. Pripatnanont $\mathrm{P}$, Vittayakittipong $\mathrm{P}$, Markmanee $\mathrm{U}$, Thongmak S, Yipintsoi T. The use of SPECT to evaluate growth cessation of the mandible in unilateral condylar hyperplasia. Int J Oral Maxillofac Surg. 2005 Jun;34(4):364-8. Epub 2005 Jan 26.

12. Hodder SC, Rees JI, Oliver TB, Facey PE, Sugar AW. SPECT bone scintigraphy in the diagnosis and management of mandibular condylar hyperplasia. Br J Oral Maxillofac Surg. 2000 Apr;38(2):87-93.

13. Chan WL, Carolan MG, Fernandes VB, Abbati DP. Planar versus SPET imaging in the assessment of condylar growth. Nucl Med Commun. 2000 Mar;21(3):285-90.

\section{Address of Correspondence}

Dr.Sanjay Pasupathy

No. 19, Saram Jayaram Nagar,

Pondicherry. India.

PIN - 605013.

sanjaypasupathy@gmail.com

\section{Authors:}

${ }^{1}$ Oral Surgeon, Sri Manakula Vinayagar Medical College and Hospital, Department of Oral and Maxillofacial Surgery

2Oral Surgeon, Sri Manakula Vinayagar Medical College and Hospital, Department of Oral and Maxillofacial Surgery

\section{How to cite this article :}

Sanjay Pasupathy, Karthik Ragupathy. SPECT/CT image fusion in unilateral condylar hyperplasia - Report of a case and review of literature. Journal of Scientific Dentistry, 2016;6(2):53-55

Source of Support : Nil, Conflicts of Interest : None declared 